Jurnal Kebidanan 09 (01) 1 - 101

Jurnal Kebidanan

http : //www. journal.stikeseub.ac.id

\title{
EFEKTIVITAS POSISI TANGAN PENOLONG DALAM PENCEGAHAN RUPTUR PERINEUM PADA PERSALINAN NORMAL
}

\author{
Mulyati Priyantini ${ }^{1)}$, Yuli Trisnawati ${ }^{2)}$ \\ 1) 2) Akademi Kebidanan YLPP Purwokerto \\ E-mail: yulitrisnawati079@gmail.com
}

\begin{abstract}
ABSTRAK
Fokus utama asuhan persalinan adalah pencegahan komplikasi untuk mengurangi angka kesakitan dan kematian ibu. Salah satu upaya adalah mencegah terjadinya ruptur perineum. Posisi tangan yang dipakai penolong persalinan kala II untuk mencegah ruptur perineum antara lain posisi tangan APN dan Varney. Penelitian ini bertujuan untuk mengetahui efektivitas antara posisi tangan penolong menurut APN dan menurut Varney dalam mencegah ruptur perineum spontan pada kala II persalinan di RSIA 'Bunda arif' Purwokerto. Penelitian ini merupakan penelitian observasional analitik, menggunakan pendekatan cross sectional dengan populasi seluruh persalinan spontan di RSIA 'Bunda arif' Purwokerto. Sampel yang digunakan adalah quota sampling sebanyak 30 sampel yang memenuhi kriteria inklusi. Metode analisis data menggunakan uji U Mann-Whitney. Hasil penelitian ini adalah Kejadian ruptur perineum pada posisi tangan menurut APN sebanyak 93,3\%, sedangkan menurut Varney sebanyak 86,7\%. Hasil analisa statistik uji U Mann-Whitney didapatkan $\mathrm{p}$ value = 0,550 (p>0,005) sedangkan $\mathrm{U}$ value $=33,000\left(\mathrm{U}_{\mathrm{h}}<\mathrm{U}_{\mathrm{t}}\right)$, artinya tidak ada perbedaan bermakna, tetapi posisi tangan Varney lebih baik dengan selisih ruptur 6,6\%. Posisi tangan penolong menurut Varney lebih efektif daripada posisi tangan menurut APN dalam pencegahan ruptur perineum spontan pada kala II persalinan, tetapi keduanya tidak memberikan perbedaan yang bermakna terhadap kejadian ruptur perineum. Penolong persalinan dapat menemukan metode yang paling tepat dalam meminimalisir kejadian ruptur perineum spontan untuk menurunkan angka kesakitan dan kematian ibu.
\end{abstract}

Keyword : Posisi tangan penolong, ruptur perineum

EFFECTIVENESS OF HANDLING POSITION IN PREVENTION OF PERINEUM

\section{RUPTURE IN NORMAL LABOR}

\section{ABSTRACT}

Main focus of delivery care is preventing the complication to reduce the maternal morbidity and mortality. One of the efforts to prevent the occurance of perineal rupture. The position hand which is used birth attendant in the second stage of labor to prevent perineal rupture among others APN and Varney hands position. The goal of this reasearch is to know the effectiveness between APN and Varney hands position to prevent spontanoeus perineal rupture in the second stage of labor in RSIA 'Bunda arif' Purwokerto. This reasearch was observational analytic by approachment cross sectional with population of this reasearch was all of spontaneous delivery in RSIA 'Bunda arif' Purwokerto and the sample used quota sampling, it's about 30 sample can be a inclusion criteria. The analyze method data used U Mann-Whitney test. The result of this experiment are precentage of spontaneous perineal rupture by APN hands position is 93,3\%, while by Varney is 86,7\%. Result of statistic analysis used U Mann-Whitney test is $p$ value $=0,550(p>0.005)$ and $U$ value $=33,000\left(U_{h}<U_{t}\right)$. It means, not significant difference, but Varney hands position better by a margin of 6.6\%. the conclusion are varney hands position is more effective than APN hands position in prevention spontaneous perineal rupture in the second stage of labor, but both not significant for perinel rupture. Suggestion : Birth attendants can find the most appopriate method to minimize perineal ruptured to reduce maternal morbidity and mortality

Keyword: APN \& Varney hands position, and perineal rupture. 


\section{PENDAHULUAN}

$\begin{array}{rrr}\text { Ruptur } & \text { perineum merupakan } \\ \text { salah } & \text { satu } & \text { penyebab terjadinya }\end{array}$ perdarahan. Ruptur perineum adalah robeknya perineum (daerah antara vulva dan anus) pada saat janin lahir (Saifudin, 2009). Salah satu penyebab terjadinya ruptur perineum adalah karena perineum tidak kuat menahan regangan pada saat janin lewat (Siswosudarmo dan Emilia, 2008). Laserasi pada vagina dan perineum dapat terjadi saat kepala dan bahu dilahirkan. Kejadian laserasi akan meningkat jika bayi dilahirkan terlalu cepat dan tidak terkendali (JNPK-KR, 2008).

Salah satu upaya untuk mencegah terjadinya ruptur perineum adalah melindungi perineum pada kala II persalinan saat kepala bayi membuka vulva (diameter 5-6 cm), yaitu saat diameter terbesar kepala melewati vulva dengan menggunakan telapak tangan penolong. Tujuan melindungi perineum adalah untuk mengurangi peregangan berlebihan (JNPK-KR, 2008). Melindungi perineum harus dilakukan dengan benar, tidak benar jika meletakkan tangan penolong pada perineum dan menekannya, karena dengan menekan akan memberikan stress pada perineum dan menghalangi pandangan penolong (Varney, 2004).
Beberapa teknik telah diperkenalkan dalam melindungi perineum, yaitu pertama menurut APN (Asuhan Persalinan Normal) dari JNPK-KR yaitu saat kepala bayi membuka vulva(5-6 cm), letakkan kain yang bersih dan kering yang dilipat di bawah bokong ibu, lindung perineum dengan satu tangan (di bawah kain bersih dan kering), ibu jari pada sisi perineum dan empat jari pada sisi yang lain dan tangan yang lain pada belakang kepala bayi, tahan belakang kepala bayi agar posisi kepala tetap fleksi pada saat keluar secara bertahap melewati introitus dan perineum. Teknik melindungi perineum yang kedua adalah posisi tangan menurut Varney yaitu tangan untuk menahan verteks bayi sama dengan perasat APN, sementara tangan yang berada pada posisi menopang perineum, diatur dengan meletakkan ibu jari pada tingkat garis tengah kunci paha pada sisi perineum, letakkan jari tengah anda pada ketinggian kunci paha pada sisi yang lain, berikan tekanan kearah jempol dan jari anda dan kemudian ke arah dalam terhadap setiap tengah perineum (Varney, 2004).

$$
\text { Manuver tangan dalam }
$$

pertolongan persalinan merupakan salah satu faktor yang mempengaruhi 
keberhasilan proses persalinan. Dalam manuver tangan yang dilakukan masing-masing mempunyai alasan dan keuntungan (Sulistyawati \& Nugraheni, 2010). Beberapa dokter percaya bahwa kontrol kepala lebih baik dalam melindungi perineum, yang lainnya berpendapat penting untuk menyangga perineum dalam tambahan pengontrolan kepala agar tercapai hasil yang maksimal. Menyangga perineum dilakukan dengan tidak meletakkan tangan pada perineum dan menekannya. Metode yang dilakukan adalah :

1. Lindungi kepala bayi dengan menggunakan handuk/duk pada kepala bayi.

2. Letakkan ibu jari anda dipertengahan dari salah satu sisi perineum dengan jari telunjuk / jari tengah di sisi perineum yang berlawanan. Secara perlahan, tekanlah ibu jari dan telunjuk ke arah bawah dan dalam untuk mengendalikan peregangan perineum. (Varney, 2004).

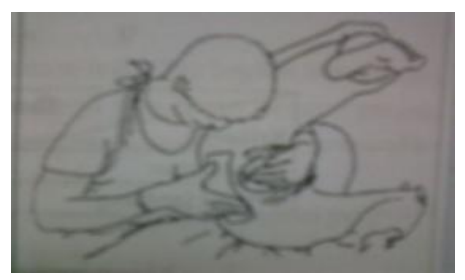

Gambar 1. Posisi menahan perineum dalam Varney (dengan ibu jari dan telunjuk)

Dalam APN (JNPK-KR, 2008), saat kepala bayi membuka vulva (5-6 $\mathrm{cm}$ ), letakkan kain yang bersih dan kering yang dilipat sepertiga bagian di bawah bokong ibu. Lindungi perineum dengan satu tangan (dibawah kain bersih dan kering), ibu jari pada salah satu sisi perineum dan empat jari pada sisi yang lain dan tangan yang lain pada belakang kepala bayi. Tahan belakang kepala bayi agar posisi kepala tetap fleksi pada saat keluar secara bertahap melewati introitus vagina dan perineum.

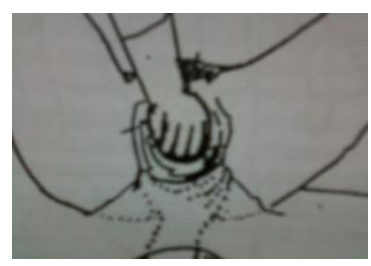

Gambar 2. Posisi menahan perineum dalam APN (dengan ibu jari dan keempat jari tangan)

Tujuan penelitian ini adalah untuk mengetahui efektivitas posisi jari dalam pencegahan ruptur perineum dalam persalinan kala II.

\section{METODE}

Jenis penelitian termasuk penelitian eksperemental, dengan pendekatan cross sectional. Cara pengumpulan data yang dilakukan dengan menggunakan data primer, yaitu dengan mengumpulkan data hasil pengamatan pertolongan persalinan sesuai kriteria inklusi yang menggunakan metode APN dan Varney. Populasi penelitian ini adalah 
seluruh persalinan spontan di RSIA 'Bunda arif' Purwokerto. Pengambilan sampel dengan quota sampling sebanyak 30 sampel yang memenuhi kriteria inklusi di RSIA 'Bunda Arif' Purwokerto. Pengambilan data ini dilakukan selama 1 (satu) bulan. Data yang sudah terolah, akan dianalisis dalam berbagai bentuk analisis, yaitu : analisis univariat dan uji $U$ MannWhitney, dengan menggunakan program komputer SPSS for Windows Versi 16.0, dengan $\alpha=5 \%(0,05)$.

\section{HASIL DAN PEMBAHASAN}

Berikut adalah data kejadian ruptur perineum spontan dan derajat rupturnya pada pertolongan persalinan kala II dengan posisi tangan penolong APN dan varney yang disajikan dalam Tabel sebagai berikut :

Tabel 1 Tabulasi silang kejadian ruptur perineum berdasarkan APN dan Varney

\begin{tabular}{|c|c|c|c|c|c|}
\hline \multirow{3}{*}{ Metode } & \multicolumn{5}{|c|}{ Ruptur perineum } \\
\hline & \multicolumn{2}{|c|}{$\mathrm{Ya}$} & \multicolumn{2}{|c|}{ Tdk } & \multirow[t]{2}{*}{$\mathrm{Jml}$} \\
\hline & $\mathrm{n}$ & $\%$ & $\mathrm{n}$ & $\%$ & \\
\hline APN & 14 & $93 \%$ & 1 & $7 \%$ & 15 \\
\hline Varney & 13 & $87 \%$ & 2 & $13 \%$ & 15 \\
\hline
\end{tabular}

1. Kejadian ruptur perineum spontan pada pertolongan persalinan kala II dengan posisi tangan penolong APN.

Berdasarkan hasil penelitian seperti pada tabel 1 diketahui bahwa dari 15 pertolongan persalinan dengan menggunakan posisi tangan APN, sebanyak 14 orang $(93,3 \%)$ mengalami ruptur perineum spontan dan yang tidak mengalami ruptur perineum sebanyak 1 orang $(6,7 \%)$. Sedangkan dari derajat ruptur perineum, paling sedikit pada derajat I sebanyak 3 orang (20\%), dan paling banyak adalah derajat II sebanyak 9 orang (60\%), artinya posisi tangan APN kurang efektif dalam mencegah ruptur perineum karena posisi tangan ini menyebabkan stress pada perineum sehingga mudah terjadi ruptur atau bahkan menyebabkan ruptur yang lebih luas (Varney, 2004).

2. Kejadian ruptur perineum spontan pada pertolongan persalinan kala II dengan posisi tangan penolong Varney.

Berdasarkan hasil penelitian seperti pada tabel 1 diketahui dari 15 persalinan, sebanyak 13 orang $(86,7 \%)$ mengalami ruptur perineum spontan dan yang tidak mengalami ruptur perineum sebanyak 2 orang (13,3\%), sedangkan derajat ruptur perineum, hanya terjadi derajat I sebanyak 8 orang $(53,3 \%)$ dan derajat II sebanyak 5 orang $(33,3 \%)$ artinya posisi tangan Varney tidak cukup signifikan, sedangkan ditinjau dari derajat ruptur, paling banyak terjadi ruptur perineum derajat satu., artinya gerakan ke bawah dan ke dalam jari akan melibatkan jaringan yang cukup dalam aksi tersebut dan mendistribusikan jaringan tambahan ke 
arah bagian tengah dari perineum, kemungkinannya mengalami laserasi, yaitu daerah yang paling besar dengan memberikan sedikit gaya pegas.

Tabel 2. Analisis U Mann Whitney pada pertolongan persalinan kala II dengan menggunakan posisi tangan APN dan Varney

\begin{tabular}{|c|c|c|c|c|c|c|}
\hline \multirow{3}{*}{$\begin{array}{l}\text { Posisi } \\
\text { Tangan }\end{array}$} & \multicolumn{4}{|c|}{ Ruptur perineum } & \multicolumn{2}{|c|}{ U Mann-Whitney } \\
\hline & \multicolumn{2}{|c|}{ Ruptur } & \multicolumn{2}{|c|}{ Tidak Ruptur } & \multirow[t]{2}{*}{$\begin{array}{c}\text { Asym.sig (2- } \\
\text { tiled) }\end{array}$} & \multirow[t]{2}{*}{$U$} \\
\hline & $\mathrm{F}$ & $\%$ & $\mathrm{~F}$ & $\%$ & & \\
\hline APN & 14 & 93,3 & 1 & 6,7 & \multirow{3}{*}{0,550} & \multirow{3}{*}{33,000} \\
\hline Varney & 13 & 86,7 & 2 & 13,3 & & \\
\hline Total & 27 & 90,0 & 3 & 10,0 & & \\
\hline
\end{tabular}

Hasil analisis menggunakan uji Mann Whitney, diperoleh angka signifikansi (nilai $\mathrm{p})=0,550$ dan nilai $U=33,000$. Karena nilai $\mathrm{p}>$ 0,05 dan $U_{h}<U_{t}=56,000$, yang berarti bahwa "tidak ada perbedaan yang bermakna kejadian ruptur perineum spontan dengan menggunakan posisi tangan APN dan Varney". Hal ini sesuai dengan teori bahwa ruptur perineum spontan dipengaruhi oleh banyak faktor. Pimpinan persalinan dan posisi melahirkan yang salah menurut sejumlah penelitian merupakan faktor salah satu sebab terjadinya ruptur perineum (Henderson, 2006).

\section{PENUTUP}

Berdasarkan hasil penelitian yang dilakukan terhadap 30 orang responden, maka dapat disimpulkan bahwa Pertolongan persalinan kala II dengan menggunakan posisi tangan APN dalam pencegahan ruptur perineum spontan, sebagian besar masih terjadi ruptur, yaitu sebanyak 93,3\% dengan derajat ruptur pada derajat II $(60 \%)$ dan Pertolongan persalinan kala II dengan menggunakan posisi tangan Varney dalam pencegahan ruptur perineum spontan, sebagian besar masih terjadi ruptur, yaitu sebanyak $86,7 \%$ dengan derajat ruptur pada derajat I (53,3\%).Hasil uji statistic menunjukkan tidak ada perbedaan bermakna pada kejadian ruptur perineum spontan dengan menggunakan posisi tangan APN maupun Varney, tetapi posisi tangan Varney lebih baik dalam mencegah ruptur dengan selisih persentase $6,6 \%$ dengan derajat ruptur lebih kecil daripada posisi tangan APN. 


\section{DAFTAR PUSTAKA}

Henderson, C dan Kathleen, J.(2006). Buku ajar konsep kebidanan. Jakarta.EGC.

Hidayat, A.A.A (2010). Metode penelitian kesehatan paradigma kuantitatif.

.Cetakan Pertama. Surabaya. Health Books Publishing.

.(2007). Metode penelitian kebidanan dan teknik analisis data. Jakarta. Salemba Medika.

JNPK-KR, (2008). Pelatihan klinik asuhan persalinan normal. Jakarta. JNPK-KR Departemen Kesesehatan Republik Indonesia.

Klemp, J. (2005). Mediolateral episiotomy. Terdapat pada: http://commons.wikimedia.org/wiki/File: Medio-lateral-episiotomy.gif. Diakses pada tanggal 1 Oktober 2005.

Leeman, L. Spearman, M \& Rogers,R.(2003). Repair of obstetrics perineal laceration. Terdapat pada http://www.aafp.org/afp/2003/1015/p158 5.html. Diakses tanggal 15 Oktober 2003.

Manuaba, I.A.C. Manuaba, I.B.G.F. \& Manuaba, I.B.G. (2010). Ilmu kebidanan, penyakit kandungan, dan KB untuk pendidikan bidan. Ed.2. Jakarta. EGC.

Notoatmodjo, S. (2010). Metodologi penelitian kesehatan. Ed. Rev. Jakarta. Rineka Cipta.

Oxorn, H. \& Forte, W.R. (2010). Ilmu kebidanan patologi dan fisiologi persalinan. M. Hakimi. Yogyakarta. Yayasan Essensia Medika.

Progestian, P. (2010). Proses melahirkan/persalinan pada manusia. Terdapat pada http://drprima.com/kehamilan/prosesmelahirkanpersalinan-pada-

manusia.html. Diakses tanggal 21 Juni 2010.

Reed, R. (2010). Perineal protector. Terdapat pada http://midwifethinking.com/2010/0 8/07/perineal-protectors/. Diakses tanggal 7 Agustus 2010.

Riwidikdo, H. (2008). Statistik kesehatan belajar mudah teknik analisa data dalam penelitian kesehatan (plus aplikasi software SPSS). Yogyakarta. Mitra Cendikia Press.

Saifuddin, A.B, Rachimhadi, T. \& Wikjosastro,G.H. (2009), Ilmu kebidanan sarwono prawirohardjo. Ed 4, Cet 2. Jakarta. Bina Pustaka Sarwono Prawirohardjo.

Santjaka, A. (2011). Statistik untuk penelitian kesehatan I. Yogyakarta. Nuha Medika.

Sulistyawati, A \& Nugraheny, E. (2010).Asuhan kebidanan pada ibu bersalin. Jakarta. Salemba Medika.

Sumarah, dkk. (2008). Perawatan ibu bersalin. Yogyakarta. Fitramaya.

Tuteur, A. (2012). Vaginal tears. Terdapat pada http://www.skepticalob.com/2012/ 02/vaginal-tears.html. Diakses tanggal 29 Februari 2012.

Wikjosastro, G.H. (2007). Ilmu kebidanan sarwono prawirohardjo. Jakarta. Bina Pustaka Sarwono Prawirohardjo.

Varney, H. (2004). Ilmu kebidanan varney's midwifery $3^{\text {rd }}$. Bandung. Sekeloa Publisher. 